http://spilplus.journals.ac.za/

348

\title{
BETEKENIS EN GEBRUIK IN 'n OMVATTENDE WOORDEBOEK
}

\author{
A.E. yan Nickerk
}

Burovan dic Woordcbock van die Afrikaanse Taal

Inlciding

'n Poging om die status van dic leksikografic as studieterrein te bepaal, word veral deur twee perspektiewe be ïnvloed. Aan die een kant is daar die leksikograwe wat hulle daarop beroem dat hulle 'n kunsvorm benefen wat hom nic by dic rigiede, objekticwe metodiek van die moderne linguistiek kan neeslê nic. Gove (1967:7) ycrwoord dié standpunt soos volg:

"Lexicography is not yet a science. It may never be. It is an intricate and subtle and sometimes overpowering art, requiring subjcctive analysis, arbitrary decisions, and intuitive reasoning".

Aan die ander kant is daar die taalwetenskaplikes wat van die leksikograwe vereis dat hulle hantering van veral die betekenis van leksikonitems, die onderliggende taalteoretiese fondament weerspieël. Weinreich (1964:408) spreek hom in sy kommentaar op Webster's Third New International Dictionary of the English Languaze ondubbelsinnig hier oor uit:

"It is disconcerting that a mountain of lexicographic practice such as an unabridged dictionary of English should yield no more than a paragraphsized molchill of lexicological theory".

Die genoemde standpunte wat oënskynlik ligjare van mekaar verwyderd lê, hoef nie noodwendig onversoenbaar te wees nie. Terwyl daar in 'n loenemende mate vaguit die taalteorie voorstellc kom van hoe daar op 'n wetenskaplike manier met die leksikon omgegaan kan word, is daar ook van die kant van leksikograwe 'n bercidwilligheid om dié insigte toe te pas en woordeboekc op 'n suiwer teoretiese grondslag te plaas.

Met dié gedagte as uitgangspunt word daar aa 'n bepaalde leksikograficse probleem, naamlik die hantering van betekenis cn gebruik gekyk, ten einde te bepaal hoe en waar die taalwetenskaplike en die leksikograaf mekaar die hand kan reik. Die voorbeeldmatcriaal is mecstal gebaseer op ongepubliseerde manusk rip yan die Woordeboek yan die Afrikaanse Taal en kan nie as 'n aanduiding van wat in 'n volgende WAT-deel gaan verskyn, beskou word nie. Dic definisies is konsepdefinisies wat aan redaksionele bewerking onderworpe is.

Die begrip "omvattend" slaan hier op enige wourdeboek - nie noodwendig die WAT nic waarbinne betekenis en gebruik in hul wydste omvang gehantcer word. Daat word terselfdertyd daarmee rekening gebou dat 'n gerigtheid op omvattende inligtingsoordrag maklik 
http://spilplus.journals.ac.za/

349

tot 'n ensiklopediese benadering kan lei, soos Gouws (1989:69) en andere al by verskeie gelcenthede tereg gewaarsku het.

Problecmstelling

In die proses on die sin of wardes wal deur taal vargestalt word, te verwoord, kom die leksikograal voor allerlei probleme te staan. Een van dic sleutelprobleme wat haas onoork oomlik lyk, is die onderskeid tussen betekenis en gebruik.

Tussen 'a quwe poliscmiese waarde, aan dic ecn kant, en die toepassing van 'n bepaalde betekenis in een of meer kontckste, aan die ander kant, lê 'n grys gebied waaroor die woordeboekgebruiker uitsluitsel wil hê. Dit is die verantwoordelikheid van die leksikograaf om sy woordeboekartikel so te struktureer dat hy nic betekenisonderskeidings miskyk en tot gebruike verskraal nic, maar terselfdertyd ook nic gebruike segmenteer as synde dit betekenis nie.

Hierdie dilemma warin die leksikograal hom bevind, word vererger deur die leit dat hy oorcenkomstig woordeboektradisie - slegs met twee kategorieë moet werk, naamlik betekenis (soos in die definisie verwoord) en gebruik (soos m.b.y. kollokasies, poc̈me en sitate aangedui). Daar kom egter dikwels grenswaardes ter sprake wat, afhangende van die perspektief van dic beoordelaar, of na die een, of na die ander kant toe kan val. Die relatiwiteit word teorelies deur onder andere die kognitiewe semantici ondersk ryf. Die kogniticwe scmantick gaan naamlik van die standpunt uit dat perseptuele kategorië 'n prototipiese struktuur het, waarbinne sekere semantiese kenmerke meer opvallend is as ander en perseptuele kategorieë sonder duidelike grense in mekaar oorgaan. (Geeraerts 1986:189)

Die implikasie hiervan vir die leksikograaf is dat hy voorsiening moet maak vir semantiese waardes wat tussen twee polisemiese onderskeidings lê, maar nog nie tot 'n prototipiese kern ontwikkel het nic en dus ook nie in 'n woordeboek as 'n nuwe polisemicse waarde aangedui word nic. Wat hierdie onderskejding betrer, moet die leksikograaf dikwels op sy taalintu isie staatmaak wat hom uiteraard aan genadelose kritick blootstel.

\section{Samewerking tussen leksikograaf en taalwetcnskaplike}

In die lig van die voorafgaande is dit noodsaaklik dat die leksikograaf 'n stel riglyne moet ontwikkel waarvolgens hy sy oordele kan vel. As hy ooreenkounstig dié riglyne handel, kan hy 'n konsekwente, verantwoordbare hanteringswyse verseker en nie allecn sy kritici trotseer nie, maar ook die gebruiker tevrede stel.

En dit is dan juis hier waar die wissclwerking tussen die leksikografie en die taalwetenskap op die voorgrond tree. Semantiese modellc, soos deur die taalwetenskaplikes ontwikkel, kan as 
http://spilplus.journals.ac.za/

teorctiese basis dien vir die leksikografiese praktyk. Maar tersclfdertyd kan dic leksikografie ook die taalwetenskap verryk, deur die teoreticse modelle aan die praktyk te toets en 'n uitspraak vor die implementecrbaarheid daarvan, al dan nie, te maak.

Betekenis as primêrc onderskciding

Die leksikograaf werk in die eerste instansie met belekenis. Daarom is dit belangrik dat hy hom primctr daartue moet verbind um betekenis te onderskci. In die meeste gevalle kan die leksikograaf by die definiëring van 'n leksikalc item volstaan met ecn of meer definisies, af hangende daarvan of die leksikale item munosemies of polisemies is. Daarnaas kan hy ' $n$ lysting van 'n klompie verteenwoordigende voorbeelde verskaf. Laasgenocmde behoort só gekies to word dat hulle die verskillende gebruiksmoontlikhede ondubbelsinnig illustreer.

Omvattende gebruikslciding

Die kognitiewe semantiek wat sedert die laat-sewentigerjarc aansienlik veld gewen het, plaas die lcksikale semantiek binne die kader van die menslike kennisorganisasic in 'n ruimer sin en gevolglik verval die tweedeling tussen rigiede betekenisbeskrywings en veranderlike, ensiklopediese wêreldkennis. (Geeraerts 1986:189) Laasgenoemdc berus op 'n magdom ervarings - vir dic doel van hicrdic besprcking, veral ons kennismaking met leksikale items, soos hulle in dic gesproke cn geskrewe kontekste gebruik word - wat die inligtingsdigtheid van ons konsepluele geheue aansienlik verhoog.

Vir die leksikograaf wal die kennisstruktuur onderliggend aan leksikale items wil verwoord, is cen van die vele implikasics van die kognitiewe benadering, dat hy die gebruiksmoontlikhedc van 'n betrokke leksikale itcm so vitpultend as moonllik moet probeer wecrgee. Dit is nie hecitemal so 'n onrealistiese ideaal as wat dit met die ecrstc oogopslag lyk nie. Waar die leksikograar oor 'n volledige, betroubare, empiries-verantwoordbare databasis beskik, sal hy in staat wees on 'n groot persentasie van die potensiële gebruikswyscs te dck.

Boonop sou hy aansienlik ruimte kon bcspaar deur van kollokasies gebruik te maak - te wete dić katcgoric waarmee ge ̈llustreer word dat sekcre leksikale items in 'n bepaalde taal in noue semantiese samchang met ander voorkom; of duideliker gestel, die verskynsel wat te make het met die semanticse en sintaktiese verbande wat leksikale itcms binne 'n bepaalde kontcks met mekaar aangaan. (Carstens 1992:1 - 2)

Kollokasies is'n inligtingstipe wat tot dusver in verklarende woordebocke onderbenut is. Dic leksikografiese waarde daarvan is nog nie duidclik genoeg uitgespel nie. Namatc die presiese struktuur en funksioncring van kollokasies taalteorelies vasgelê word, kan leksikograwe dit sinvol aanwend om gebruik op 'n omvatlende, maar lerselfdertyd ckonomiese wyse te illustreer. 
http://spilplus.journals.ac.za/

351

Strukturering van gebruiksgevalle

Dit is juis die potensiaal van 'n leksikale item om in 'n verskeidenbeid kontckste op te tree wat die leksikograaf soms laat voei dat hy - veral as hy gebruikersvriendelik wil wees - sodanige kontekste duidelikheidshalwe moet struktureer. Vergeiyk in die verband die WAT se hantering van die leksikale item lekker.

Benewens die definisie "Wat genot verskaf", word daar na die aanloop "s I.d. volgende verbande", te kenne gegee dat die genoemde betekeniswaarde t.o.v. smaak; ander sintuie; asook die weersgesteldheid, omgewingstem peratuur of klimaat kan geld.

Waar hierdie toepassingsmoontlikhede onderskei en as sodanig gemerk word, het dit die bykomende voordeel dat funksicwisseliag, veral by werkwoorde en byvoeglike naamwoorde, nakliker georden kan word. 'n Klassifikasie van gebruiksmoontlikhede is byvoorbeeld by die byvoeglike naamwoord van waarde, omdat dit die ordening van bywoordclike gebruike vergemaklik. By lekker se toepassings (1) en (2) is daar na die aanloop "ه Ook byw.", telkens die voorbeeld gegee wal in die betrokke kontcks inpas. By toepassing (1) sou daar byvoorbeeld koo gestaan het: "Batteryhoenders smaak nie so lekker vars soos plaashoenders nie." en by toepassing (2) "Die kat se pels voel lekker sag."

or daar werklik regverdiging daarvoor is om in sekere gevalle 'n strukturering van gebruiksmoontlikhede te gee, terwyl dit in ander gevalle nie gedoen word nie, bly 'n ope vraag. Een van die groot probleme wat sodanige hantering van gebruiksgevalle skep, is dat die woordeboekgebruiker die foutiewe afleiding kan mank dat dit ook 'n tipe betekenisverdeling verondcrstel. Uit die argumente wat volg, behoort verder te blyk dat die leksikografiese hantcring van gebruiksonderskeidings vra om 'n omsigtige benadering.

Verwarring t.o.v. definisic en aanloop

Waar sommige gebruiksgevalle in die woordeboekartikel as toepassings gemerk en selfs genommer word, kan dic lcksikograaf maklik fouteer deur gebruiksmoontlikhede per def inisie as ' $n$ stuk betekeais aan te bied. Hiermee mislei hy die gebruiker. By lelik is die WAT'definisie "Wat onaangenaam of ongunstig is en ... negatief ervaar word" aanvanklik foutiewelik aangevul met variasiedefinisies na die aanloop "n I.d. volgende verbande". By die eerste toepassing staan daar "Onaangenaam om te sien; met 'n onaantreklike of afstootlike voorkoms", by die tweede toepassing "Onaangenaam om te hoor; met 'n onwelluidende klank", by die derde toepassing "Onaangenaam a.g.v. afkeurenswaardige of onbehoorlike of onbetaamlike gedrag of hoedanigbede", ens. Die bewoording by (1), (2) en (3) kan vervang word met "t.o.y. gesig", "t.o.v. geboor", "t.o.v. gedrag of hoedanighede", ens., ten einde daarvan die toepassings te maak wat dit wel is. 
http://spilplus.journals.ac.za/

Dit moet duidelik uit die leksikograaf se formulering blyk dat dit hier gaan om die toepassing van 'n bepaalde betekeniswaarde op 'n spesifieke saak, terrein, periode, ens. Met die aanlopie "t.o.r." kan die gebruiksfeer vasgepen word. Omgekeerd, waar die leksikograaf nie met behulp van "t.o.v." die gewcnste gebruiksonderskeiding kan maak nie, moet by begin wonder of hy aie met 'n nuwe betekenisonderskeiding te make het cn dus opnuut moet begin definieer nie.

Polisemiese onderskeidings n.a.v. plus-en minuswaardes

Word dic leksikograal met 'n leksikale item gekonfrontecr wat in 'n groot verskcjdenheid kontekste kan optree, moet hy hom allereers afvra of dic legio "gebruike" nie juis die ontwikkeling van nuwe polisemiesc onderskeidings sinjaleer nie.

Dié gedagte sluit aan by wat Landheer (1991:54 - 57) in sy artikel "Textsemantiek en Lexicale semantiek" oor belekenis en gebruik te sê het. Hy bepleit 'n relativering van die eensydige siening dat alleen die betekenis van ' $n$ leksikale itern deurslaggewend is vir dic betekenis van 'n sin of grotcr konteks. Landheer (1991:55) wys daarop dat 'n noukeurige ontleding van dic teks en sy pragmaties-semantiese konteks, dit vir ons moontlik maak om dic betekenis van leksikale items te bepaal en te verklaar. Na aanleiding hiervan spreek hy kritiek uit teen Geeraerts (1989) sc beklemtoning van "wat er in cen woord kit", omdat daar na sy mening ook veel in die konteks of situasic sit.

Die taalwetenskap bied die leksikograaf 'n verskeidenheid meganismes wat hy kan aanwend om poliscmiese betekeniswaardes te isoleer. Hier word net na enkeles vcrwys.

Ten einde te bepaal of hy met ' $n$ nuwe polisemiese onderskeiding, al dan nie, te make het, kan dic leksikugraal byvourbecld dic vervangingsbeginsel toepas. Sodoende kan hy agtcrkom of daar betekenismatig iets an die oorspronklike betekenis toegevoeg, of iets daarvan weggelaat is. Deur lotery te definieer as "Handeling of proses van te loot", maak dic leksikograaf voorsiening vir gebruike soos dic volgende: "Geen lotery sal by die basaar toegelaat word nie. Hulle wou met 'a lotery geld vir die nuwe skoolsaal insamel, ens." Kom by by 'n geval soos die volgende: "Ek het 'n lotery gewen", klop die definisie nie meer nie en is moet hy 'n nuwe poliscmiese onderskeiding maak.

Ook komponentontleding kan met vrug as onderskeidingsmcdium gebruik word, solank die leksikograal in gedagte bou dat daar sekere beperkings aan verbonde is. Hy kan byvoorbecld nie sy definisie uitsluitlik op die geabstraheerde semantiese komponente bou nie.

Verder beklemtoon Landheer (1991:60 - 63) die waarde van "hedges" (woorde of frascs wat dic betekenis van dic leksikale item wat deur hulle bepaal word, relativeer). Wanneer 'n mens byvoorbeeld sou sê: "Jy is darem 'n regıe bobbejaan!", is regte die "hedge" waarmec dic disjunkıc 
http://spilplus.journals.ac.za/

353

betekeniswaarde van bobbejaan gcaktivcer word. Toutologieë soos byvoorbeeld, "'n Afspraak is 'n afspraak", waarmee te kenne gcgec word dat 'n af spraak icts heiligs is wat nagekom behoort te word, het volgens Landheer (1991:64) ook waarde as onderskeidingsmeganisme.

Die leksikograaf moet dus, veral met behulp van die sinjale wat die taalweterskaplikes tot sy beskikking stel, op die uitkyk wees vir plus- of ninuswaardes wat op 'n betekenisverruiming of betekenisverenging dui.

Die genocmde wysigings lei dikwels tot 'n figuurlike verdieping wat so ver van dic oorspronklike betekeniswaarde verwyderd lê dat dit as 'n aparte betekenisonderskeiding gereken kan word. Ondersteuning hiervoor kry ons vanuit die kognitiewe semantiek waarbinne daar aanvaar word dat 'n leksikale konsep 'n betekenispotensiaal het wat mécr is as die som van alle geregistreerde gebruikswyses $y_{a n}$ 'n betrokke jeksikale item. Die semantiese vermoë van die individuele taalgebruiker maak dit naamlik vir hom moontlik on leksikale itcons op nuwe, as 't ware "ongehoorde" wyses te gebruik. Deur die afwykende gebruiksmoontlikbede te weerspjeël, maak dic leksik ograaf — om Landheer (1991:55) se terminologie te gebruik — nie alleen vir besiaande nie, maar ook bestaanbare betekenisse yoorsiening.

Die leksikograaf moet daarteen waak dat semantiese inligting wat vanuit die konteks saamgesels, hom op 'n dwaalspoor plaas. Hy moet versigtig wees om nie algou te aanvaar dat kontekstuecl bcpaalde betekenisaspekte ook inherente woordbetekenisse is nie. Dit is dan ook hiesleen dat Ruhl (1989) in sy publikasie On Monosemy: A Study in Lingnistic Scmantics waarsku wanneer hy leksikograwe daaryan beskuldig dat hulle té maklik aanvaar dat elke leksikale item noodwendig 'n polisemiese betekenisstruktuur het. Hierdie "overspecification" moet vermy word.

Sinonimie cn antonimie as onderskeidingstriteria

Landhecr (1991:59) temper die genoemde beskuldiging van Rubl wanneer hy daarop wys dat betekenisverhoudings soos sinonimic en antonimie, subtiele aanduidings kan gee van die fyner betekenisskakerings van 'n betrokke leksikale item - 'n waarneming wat vir die leksikograaf van groot waarde kan wees.

Die verskillende polisemiese waardes van een en dieself de leksikale item het dikwels verskillende sinoniem- of antoniemwaardes, maar dieself de geld nie ten opsigte van verskillende toepassings rie.

Wat wel waar is, is dat die konteks waarbinne'n betrokke leksikale item gebruik word, kan bepaal watter sinoniem- of a toniemwaarde ter sprake kom. Dit sou dus nie juis wces om by toepassings wat konteksleiding verskaf, betekenjsverbande soos sinonimie en antonimie aan te dui nie. "n Vergelyk-verwysing sou desnoods in die gevalle gebruik kon word. 
http://spilplus.journals.ac.za/

By lekker word "t.u.v. smaak" en "t.o.v, reuk" as toepassings gamerk en "smaaklik" (vgl. "Dic kos proe smaaklik.") en "geurig" (vgh. "Die kruietee ruik geurig.") sou byvoorbecld in die genoende kontekste as gedecltelik sinoniem aan lekker beskou kon word. Dit beteken nie noodwendig da! lekker polisemiese onderskeidings behoort te hê nie. Wat vir die sintuie aangenaam is, bly aangenaam, of dit nou op smaak of reuk slaan.

By lckt or lees die definisic: "Dosent aan 'n tersiêre onderwysinrigting, veral 'n universiteit, wat nie die status van 'n professor het nie; ook soms, iem. wat ander gevorderde of gespesialiseerde ondertig gee". Met die voorbceldmateriaal word aangedui dat lektor eerstens t.o.v. 'n manlike of vroulike persoon gebruik kan word, maar tweedens uitsluitlik op 'n manlike persoon dui. In Afrikaanse Sintaksis onderskei Ponelis (1979:19) in die verband tussen die generiese en eksempiariese gebruik van 'n betrokke leksikale item.

Word met lektor manlike én vroulike persoon bedoel (vgl. "n Lektor se salaris vergelyk swak met die van iemand in die privaatsektor."), het die betrokke Icksikale item geen antoniem nie. Word lektor slegs op 'n manlike persoon van toepassing gemaak (vgl. "Ons lektor rig Dagbreek se rugbyspan af."), staan dit teenoor lektrise. Antonimie is in die laasgenoemde geval deur die gebruiksfeer bewerkstellig, maar die anwesigheid daarvan impliseer nie noodwendig 'n nuwe polisemiese onderskeiding nie. Of 'n lektor manlik of vroulik is, verander nie aan die kernbetekenis daarvan nie. Manlik en vroulik is hier bloot gebruiksonderskeidings.

Uit die genoemde argumente blyk dit dat sinonimie en antonimie nic as absolute maatstawwe beskou kan word om tussen betekenis en gebruik te onderskei nie.

\section{Oorganklikheid en onoorganklikheid}

Oorganklikheid en onoorganklikheid bring ook hul kwota probleme mee. Daar kan gefouteer word deur die oorganklike en on oorganklike vorm van een en dieself de werkwoord as aparte betekenisonderskeidings te hanteer. Die konteks waarbinne 'n bepaalde werkwoord optree, bepaal of hy oorganklik sal wees of nie. By lek waar dié onderskeid aanyanklik as 'n semantiese onderskeid gehanteer is, is later met een definisie, naamlik "Deur 'n ongewenste opening, swak plek, ontoer eikende isolasie, e.d. voortdurend op betreklike klein skaal (laat) ont snap of binnedring", volstaan. Voorbeeldmateriaal soos "Die geut lek as dit reën." en "As die sak begin mielies lek, moet die boer dit toewerk.", kan gebruik word om oorganklikheid en onoorganklikheid te illustrecr.

Kunsmatige sambreeldefiniëring

As die definisie wat as uitgangspunt geneem word, te wyd gestel is, is dit moontlik om feitlik alle betekenisonderskeidings verkeerdelik as gebruike onder so 'n oorkoepelende of 
http://spilplus.journals.ac.za/

355

sambrceldefinisie saam te vat. 'n Definisie wat te veel verkap is, lei wecr daartoe dat die teksikograal poliscmiese onderskeidings maak wat nie bestaan nie. lewers tussen die genoemde pole moet die leksikngraaf'n gouc middewcg vind.

By lêplek is alles aanvanklik so resloos ingedecl dat die betckenis tot so 'n kunsmatige sambreeldefinisie verskraal is. Die definisie lui: "Plek waar iem, of iets woon of hou" en die toepassings "t.o.v. plek waar mense tydelik bly" en "t.o.y. plek waar iem. gedurig, soms tot vervelens toe hou; dikw. m.d. doel oro lecg te lê of kwaad te doen" behoort aparte betekenisonderskeidings te gewees het.

By lcaterecs is die definisie "Fees waarmee die begin v.d. lente gevier word" ook 'n sambreeldef inisic met "(1) T.o.v. die tradisionele godsdienstige fees" en "(2) T.o.v. die moderne sosiale geleentheid" verkeerdelik as gebruiksonderskeidings. In dié geval is 'n poliscmicse onderskeid geregverdig. Wat aanvanklik 'n godsdienstige fees was, is later gesekulariseer en daar is yan twee verskillende tipes fceste sprake. Sodanige hantering sal boonop die leksikograaf sc taak vergcraklik wanneer hy lentekoningin in terme van leatcfees wil definiecr. Die gebruik om 'n lentekoningin te kics kom slegs by die sckulère fees voor en as lentekoningin verklaar word met "Skoonheidskoningin wat by die lentefees gekies word", sal eksplisering van betekenis rodig wees. Dit moet in terme van betekenis- en nie gebruiksonderskeidings nie, gedoen word.

Presisering van betekenis met "meer bep." en "veral"

Dic bewoording "mecr bepaald" en "veral" word meermale gebruik om in 'n definisie aan te dui dat die betrokke leksikale item, athoewel dit iets algemeens beteken, eintlik 'n meer spesifieke betekeniswaarde het. In die terminologie van die kognitiewe semantiek sou dit daarop neerkom dat sommige betekeniskenmerke van 'n leksikale item 'n groter relevansie bet as ander, maatr dat hulle medebepalend is om die perseptuele kategorie van die leksikale item te omskryr. (Geeraerts 1986:195)

By lot lui die definisie byvoorbeeld "Handeling of proses van te loot; meer bep., godsdienstige handeling waarmee die beslissing vao God gevra word". En by lểhok "Hok vir lêhenne of ander pluimvee wat vir lêdoeleindes aangehou word; veral, lckkou". Streng gesproke word daar met dié formulerings geïmpliseer, "nie dit nie, maar eintlik iets anders", en in diê opsig verteenwoordig dit twce def inisies in een.

Waar die leksikograaf voel dat hy "meer bep." of "veral" in sy definisie moet inbou, moet hy besef dat daar hecl waarskynlik van twee betekenisonderskeidings sprake is. As hy sy sitate kan skei, is dit beter om liewer die polisemiese wardes apart te bou. Alleen by gevalle waar die sitate mocilik skeibaar is - soos wanaeer 'n bepaalde betekenismoment as 'I ware onderweg is na ' $\mathrm{n}$ 
http://spilplus.journals.ac.za/

nuwe polisemiesc waardc - en dic onderskeid tussen betekenis en gebruik vervaag, is "meer bep." en "veral" geregverdig.

SIoI

Absolute maatstawwe vir die onderskeid tussen betckenis en gebruik kan kwalik vecrgelê word. Betekenis is te kompleks om in waterdigte kompartemente ingedeel te word en dic leksikograaf hel mel 'n dinamiese taal te make wat sy bakens voortdurend verskuif. Dit beteken nie dat dic leksikograaf die belangrikheid van taalwetenskaplike insigte $k$ an versmaai nie.

Om die geloof waardigheid van die leksikografic as gesaghebbende studicter rein te verseker, kan die leksikograaf nie anders as om sy "natuurlike" aanvoeling aan die taalteorie te toets nie. Hy moet hom van verskeie laalwelenskaplike modelle bedien en met 'n gesonde kritiese ingesteldheid uit elkeco díl probecr haal wat hom in sy hantering van leksikograficse probleme, 'n fraksie nader aan dic waarheid kan bring. Dan kan dic leksikografie op wetenskaplikheid aanspraak mak en is dit nic nodig om swak leksikograliese praktyk te probeer vergoelik deur dit as "kuns" af te maak nic.

BIBLIOGRAFIE

CARSTENS, A. 1992. Kollokasies: vryeverbindings of lekseme? Siti-Afrikaanse Tydskrif vir Taolkunde, 10(1): $1-11$.

GEERAERTS, D. 1986. Woordbetekenis - Een overzichl van de lexicale semantiek. België: Acco.

GEERAERTS, D. 1989. Wat er in een woord zit - Facesten van de lexicale semantiek. Leuven: Peeters.

GOUWS, R.H. 1989. Leksikografie. Pretoria, Kaapstad: Academica.

LANDHEER, R. 1991. Tekstsemantiek en lexicale semantiek. Jaarboek van de Stichting Instituut voor Nederlandse Lexicologie: $53-66$. 
http://spilplus.journals.ac.za/

357

PONELIS, F.A. 1979. Afrikaanse Sintaksis. Preloria: Vал Schaik.

RUHL, C. 1989. On Monosemy. A Study in Linguistic Semantics. New York: State University of New York Press. 